\title{
La pena de muerte se olvida de la delincuencia
}

\author{
En memoria de Vicente Campos $S$. \\ Físicamente desaparecido el 3 de mayo de 1994.
}

Los altos niveles de criminalidad en el país han traído una vez más a la discusión pública el tema de la pena de muerte como medida que podría frenar la delincuencia. Otros no llegan a tal extremo y sólo piden que se aumenten las penas de prisión y se implante la prisión perpetua para determinados delitos. En realidad, las esperanzas en el derecho penal se han exagerado.

Las normas de derecho pretenden encauzar conductas, es decir, orientar comportamientos de modo que éstos no pongan en peligro a la sociedad y permitan la libre participación en la misma de cada individuo, pero no son las únicas. El control social, constituido por las reglas de conducta, las sanciones y un proceso de control, no sólo se realiza por medio de las normas del derecho, sino que también por medio de las normas religiosas y morales, así como por medio de los usos sociales. Las primeras, las normas del derecho, se caracterizan porque pueden ser aplicadas por medio de la fuerza del Estado; por el contrario, las otras carecen de la posibilidad de ser impuestas coactivamente. El control social, se ejerce por medio de las instituciones formalizadas o creadas deliberadamente para someter a control y también por medio de los ministros de los cultos religiosos, los maestros, los orientadores sociales, los psiquiatras, los psicólogos, la familia, los amigos, etc. Precisamente, ellos son el primer nivel que proporciona la orientación de de las conductas.

De otro modo, las instituciones, los tribunales y los funcionarios crecerían, el tamaño del Estado alcanzaría niveles inadecuados y éste siempre sería incapaz para resolver el problema de la delincuencia. La intervención estatal en la vida privada sería absoluta y los niveles de confrontación social, derivada de la presión oficial, harían difícil conservar la cohesión entre los diversos sectores. Por ello es que las situaciones a resolverse en los tribunales pertenecen a un pequeño grupo, elegido por los legisladores, quienes determinan en una ley lo que puede ser conocido por los jueces, siguiendo determinados criterios.

En el último nivel de un Estado democrático de derecho se encuentran las sanciones penales, a las que se recurre como medida extrema que puede aplicarse a las conductas más graves y peligrosas. Desde luego que de estos comportamientos, no todos llegan a ser sancionados efectivamente, algunos de ellos ni siquiera llegan a conocimiento de la policía o de los tribunales, ya sea por temor, debido a la poca confianza en las instituciones implicadas, por transacciones privadas entre delincuente y víctima, por falta de información, etc. En otros casos, ya iniciado el proceso penal, no se logra comprobar adecuadamente la responsabilidad de una persona como causante de un delito. También sucede que el tribunal de jurados, en los 
casos en que conoce, no obstante haberse probado dicha responsabilidad, decide declarar inocente al reo. Ocurre, además, que habiéndose dictado sentencia condenatoria, ésta no se puede cumplir, debido a que el delincuente no ha sido capturado. En fin, existe una enorme gama de posibilidades que nos permite afirmar que es imposible que todos los delitos cometidos en una sociedad sean efectivamente sancionados.

Esto también nos hace evidenciar que las sanciones penales no son la panacea para terminar o disminuir la delincuencia. Para que esto último ocurra, se necesita un programa de política criminal global, el cual debe comprender no sólo medidas policiales y judiciales, sino también reformas legislativas y administrativas, y especialmente medidas de largo plazo que impliquen a toda la sociedad salvadoreña como el empleo, la vivienda, la salud, la alimentación, la educación, etc. ¿Cómo puede disminuirse exitosamente la delincuencia patrimonial con medidas policiales y judiciales, si existen altos niveles de desempleo? ¿Cómo puede reducirse el nivel de delitos de libramiento de cheques sin fondos, si no existe una política económica para apoyar a la pequeña y mediana empresa? ¿Qué capacidad se puede tener para contrarrestar adecuadamente a las "maras", si no existen programas realistas para mejorar la situación de los niños y jóvenes de escasos recursos? ¿Cómo puede contrarrestarse el lavado de dinero y otras actividades relacionadas con las drogas, si el nivel de vida ofrecido a los potenciales delincuentes, fácilmente excede el estado de pobreza en el que se encuentra la mayoría de la población salvadoreña? En fin, hay una serie de situaciones delictivas, que con medidas policiales y judiciales, únicamente se pueden contener por breve tiempo, pero luego terminarán por imponerse.

Antes de entrar en las razones divulgadas universalmente y que fundamentan el fracaso de la pena de muerte ante la delincuencia, cabe hacer una mención breve de las principales teorías sobre dicha pena, que ulteriormente nos servirán para examinar su improcedencia.

La teoría más tradicional, llamada retributiva, es aquella que considera que el mal no debe quedar sin castigo, que la pena debe imponerse, fun- dada en razones éticas o religiosas y no en razones de utilidad social, pues sería convertir al hombre en un instrumento al servicio de un proyecto de la sociedad, desconociendo que él es el fin de la actividad del Estado. Kant plantea la siguiente hipótesis. Si los habitantes de una isla decidieran separarse y dispersarse por el mundo, los delincuentes cuyas sanciones no hayan sido aplicadas deben serlo. El castigo debe aplicarse, aunque resulte inútil para la sociedad — pues ésta dejará de existir-, con el único propósito de que todos comprendan el valor de sus actos.

Para Hegel, otro expositor de la misma teoría, la pena se justifica por la necesidad de restablecer la voluntad general, representada por el orden jurídico. Aquello que en la ley se ha definido como delito para proteger determinados bienes jurídicos resulta negado por la voluntad especial del delincuente, cuandó éste transgrede la ley.

Otro planteamiento sobre la pena, se deriva de las teorías preventivas, las cuales se alejan de la idea de justicia y se fundamentan en un sentido utilitarista de la pena: ésta servirá para inhibir el futuro delito. La pena no debe reducirse al castigo como respuesta ante la infracción cometida, sino que la pena aplicada debe estar orientada a evitar que se cometan infracciones. Estas teorías se dividen en dos clases: la teoría de la prevención especial, que dirige su atención al delincuente en particular, esperando que la pena tenga en él un efecto resocializador, y la teoría preventiva general, que confía en que la pena sirva para intimidar a los delincuentes potenciales y para robustecer la conciencia jurídica de todos los miembros de la comunidad, inhibiéndolos para cometer delitos.

Modernamente, la retribución es admitida junto con la prevención, con el objeto de que la pena impuesta no exceda el límite de la responsabilidad individual, alegando razones de utilidad social. De este manera, no debería imponerse a un delincuente una pena teniendo en cuenta sólo la necesidad de intimidar a la generalidad de los ciudadanos, pues ésto nos llevaría a aceptar casos como el de una sanción extremadamente grave por hechos cometidos imprudentemente.

La pena de muerte ha estado ligada histórica- 
mente a las teorías retributivas. La muerte es la retribución por el pecado cometido. Pero la teoría retributiva no está interesada en la realidad, es decir, en examinar la problemática de la aplicación de la pena, y con razón, pues en la práctica sólo algunos casos reciben castigo, con lo cual el valor justicia que la fundamenta se relativiza aún más en la vida social. El error judicial no es un problema que atañe a esta teoría, porque ha renunciado a cualquier examen de la realidad social.

En la teoría preventiva especial, la pena de muerte carece de sentido, puesto que con ella terminaría la existencia del delincuente y sus posibilidades de resocialización. En la teoría de la prevención general, que toma en cuenta la realidad práctica, la pena de muerte no tiene mucha esperanza de ser eficaz, porque el delincuente potencial muy pocas veces alcanza el grado de racionalidad que esta tesis supone. El delincuente no toma en cuenta la amenaza de ser condenado a muerte, sino que en la mayoría de los casos se deja arrastrar por infinidad de motivos que le hacen perder de vista las posibilidades de ser condenado a muerte. Si acaso su motivación cuenta con esta intimidación, pocas veces se inhibe, dado que casi siempre analiza en el sentido contrario al del legislador: el delincuente potencial visualiza las posibilidades de no ser descubierto, es decir, su cálculo es optimista.

Las opiniones en favor de la pena de muerte son las siguientes: (a) la sociedad tiene que defenderse o protegerse de los criminales y cuando el Estado decide matar al delincuente lo hace en legítima defensa; (b) la ley del talión, que se fundamenta en que ante una agresión delictiva corresponde una reacción similar por parte del Estado: el que mate, debe ser eliminado; (c) la necesidad de reconocerse en las víctimas de delitos y ser solidario con su deseo de venganza. Los que opinan así, preguntan: ¿no apoyarías la pena de muerte si mataran a tu hijo o a tu hermano?; (d) con la pena de muerte los delincuentes y los delincuentes potenciales se inhibirán de cometer delitos por temor a ser eliminados. También existen opiniones a favor de la pena de muerte, que no explican su fundamento, limitándose a dramatizar el asunto.

Analicemos estas opiniones. Para responder a la primera de estas opiniones sobre la defensa y protección, partamos de los elementos que el derecho penal exige para excluir de responsabilidad a quien se defiende: la legítima defensa tiene por objeto detener la agresión o reducir su peligrosidad, se justifica cuando la defensa empleada es necesaria para impedir el ataque y cuando éste no se haya provocado suficientemente por quien se defiende. Siguiendo el orden de estos principios, se advierte que en El Salvador la pena de muerte fue incapaz para detener la ola delincuencial, cuando estuvo vigente. A pesar de ejecutarse algunas penas de muerte, la delincuencia no se detuvo y el nivel de peligrosidad delictiva normal en aquella época no se vio conmovido por dichas ejecuciones. En el propio Estados Unidos, la ejecución de la pena de muerte por los estados que la admiten, no permite ser optimistas para considerar que dicha pena detiene o reduce la delincuencia. Nadie pasa por alto que nada es capaz de detener absolutamente la delincuencia, pues ésta es connatural a la vida social. Lo único viable es la reducción de los crímenes, lo cual no puede lograrse por medio de la aplicación de esta pena.

La necesidad de la pena de muerte sólo se justificaría si la sociedad no tuviese otro medio para defenderse y en una sociedad democrática, siempre encontramos alternativas para reducir la agresión criminal. En cuanto a la legítima defensa, hay que recordar que los estudios de sociología criminal han comprobado que las mismas sociedades son las productoras de las conductas criminales. Cuando la sociedad anuncia exquisitos alimentos, lindas casas, excelentes vehículos, joyas, bebidas, diversión, mujeres guapas e inteligentes, etc., y no

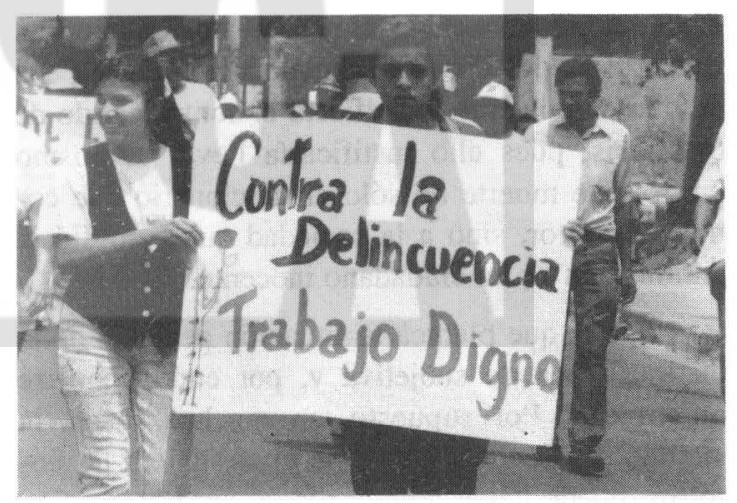


ofrece a la mayoría de sus miembros los medios legítimos para acceder a esas ofertas, éstas pueden considerarse como una provocación para cometer determinados delitos. Por lo tanto, la sociedad es responsable en buena medida de ciertas agresiones de las cuales es víctima ella misma.

Para apoyar la reimplantación de la pena de muerte se ha dicho con amplio despliegue periodístico que "hay que tomar fuertes medidas para terminar con la delincuencia". Sin embargo, los mismos apologistas saben que no hay medida alguna que haga desaparecer la delincuencia, si no es la desaparición de la propia sociedad. Ninguna comunidad en el mundo está libre de la delincuencia, pues ésta es connatural a toda sociedad y el único proyecto viable se conforma con la disminución de la criminalidad a niveles aceptables, que permitan una adecuada participación social. Además, existe un proceso de criminalización que se produce cuando las fuerzas políticas y los poderes reales de una sociedad, por medio del órgano correspondiente, establecen las conductas que constituyen delito.

En cuanto a la tesis de la ley del talión hay que decir que es imposible llevar la justicia al mundo social. En este sentido, pues no es posible que todas las acciones delictivas reciban respuesta penal. Precisamente, además, para la sociedad sólo puede tener sentido aquello que mejora sus condiciones de vida y la participación individual de sus integrantes. Sin embargo, retribuir cada acción o, siendo realistas, las conductas conocidas y comprobadas, haría imposible el mantenimiento de la cohesión social, necesaria para que la misma se desarrolle. Las justicia trasciende a la vida social efectiva, no en consideración al mundo teórico. Los errores del Estado en la ejecución de la pena de muerte ponen de manifiesto el contrasentido de esta tesis, pues ello justificaría llevar al mismo proceso de muerte no sólo al funcionario que cometió el error, sino a la sociedad que permitió la eliminación de un ciudadano inocente.

La tesis que plantea la situación personal de la víctima, peca de subjetiva $y$, por ende, requiere objetividad. Por supuesto, en muchos casos, la víctima, pudiendo tratarse de cualesquiera de nosotros, puede llegar a desear la muerte para quien le ha causado perjuicio. Pero no es cierto que a este deseo de venganza natural pueda dar respuesta positiva en todos los casos, pues, tal como lo hemos examinado, no toda conducta delictiva es sancionada. Además, si tuviéramos que tomar en cuenta la situación particular de cada miembro de la sociedad, no sería posible tipificar de modo general el delito y su pena. También es válida la siguiente pregunta para negar la pena de muerte: ¿apoyarías la pena de muerte si ejecutaran a tu hijo o a tu hermano inocente, acusándolo de criminal? De lo que se trata es de posibilitar la vida social, lo que no quiere decir negar al individuo, sino realizar el bien común de la mayoría de los componentes de la sociedad. Para ello, a la hora de decidirnos por la pena de muerte, debemos tomar en cuenta no lo que convenga al interés particular, sino al general. Este no lo descubrimos examinando nuestros sentimientos particulares, de manera subjetiva, sino los intereses de la mayoría, que sólo el examen objetivo nos puede ayudar a descubrir.

A la tesis que defiende la pena de muerte para que los delincuentes potenciales se inhiban, hay que tomar en cuenta lo dicho acerca de la teoría de la prevención general. En efecto, esa sanción no es capaz de posibilitar los resultados anunciados. En ningún país del mundo, ni siquiera aqui, en el pasado, ha sido posible reconocer que el delincuente potencial analiza la probabilidad de ser eliminado físicamente cuando se dispone a cometer delitos. Famosos son aquellos ejemplos que citan los detractores de la pena de muerte, cuando en Europa se ejecutaban los carteristas en las plazas públicas. La ejecución no impedía que el mismo df́a, los ladrones aprovecharan el alboroto para apoderarse de las carteras de los asistentes a la plaza pública.

Mayor probabilidad de éxito, dentro de una política criminal global, podría tener una mayor preparación policial, judicial y administrativa, para asegurar el cumplimiento efectivo de las causas que excluyen la responsabilidad. Esto casos no pueden ser considerados como pena de muerte adelantada, sino como respuesta legítima ante una agresión. En nuestro Código Penal, por ejemplo, encontramos figuras como la defensa putativa de la propiedad, por medio de la cual se considera 
inculpable al que en la creencia razonable de una agresión inminente, rechaza durante la noche o emplea violencia contra el intruso, cuando éste escala o es encontrado en el hogar, siempre que las circunstancias revelen la probable agresión. Asimismo, los casos de legítima defensa y de cumplimiento del deber excluyen de responsabilidad penal. Sin embargo, actualmente estos hechos funcionan por un camino distinto, presumiendo culpable al que mata a un agresor supuesto o real, en vez de considerarlo inocente, cuando no se ha probado su responsabilidad.

Estaríamos de acuerdo con quienes opinan a favor de la pena de muerte sin presentar razón alguna, si ésta se aplicara especialmente al funcionario corrupto que perjudique al Estado con sumas elevadas, a los responsables de las grandes empresas que perjudiquen al fisco, al secuestrador, al traficante de niños y a quienes lavan dólares, para citar algunos ejemplos. Pero suponemos que cuando se habla de pena de muerte sólo se piensa en otro tipo de criminales: el desintegrado, el marginado, el inculto, el que ejecuta las decisiones de otro, etc., y en general, aquel que no tiene importancia para el sistema, porque carece de poder.

Según las encuestas de opinión pública, la aceptación de la pena de muerte por parte de la ciudadanía es mayoritaria. En consecuencia, para algunos políticos, el tema se convierte en un proyecto electoral beneficioso, independientemente de que disminuya o no la criminalidad.

En realidad, el proyecto de la pena de muerte se olvidó de la delincuencia, para pasar a formar parte de otro grupo de proyectos. Ahora sólo es materia de política electoral, pues estamos claros que como medio de combate a la delincuencia carece de sentido. También se instrumentaliza como proceso de catarsis social, por medio de la cual, la comunidad libera energías en dirección distinta a la responsabilidad institucional por los niveles de criminalidad. Las razones antes apuntadas contra la pena de muerte, no pasan desapercibidas. De hecho, se reconocen con poco esfuerzo, en los momentos de reflexión. Pero hay que reconocer que las razones en contra de la pena de muerte aquí señaladas, no pueden convencer a aquellos que han descubierto otras ventajas, las cuales perderían sentido si se discutieran de cara a la comunidad.

Los datos muestran que todavía no existe una política criminal. En realidad, las acciones policiales no son parte de un proyecto global del combate contra la delincuencia, sino más bien medidas parciales que tienden a disminuir la crítica de los diversos sectores sociales por la falta de seguridad ciudadana. Probablemente, esto no se deba a la falta de voluntad de ciertos funcionarios, sino a los hechos: se carece de medios, de capacidad y de proyecto común que comprometa a los diversos órganos e instituciones. Estas carencias son responsabilidad de quienes esconden intereses diversos contra la paz y seguridad.

Finalmente y en consideración a la brevedad, no es necesario ahondar en cuestiones relativas a la prohibición constitucional de la pena de muerte, al compromiso asumido por El Salvador internacionalmente para no reimplantarla al firmar el pacto de San José ni a otros temas técnicos.

A. H. C. S. 